\title{
Thermal homeostasis in the newborn puppy: behavioral and physiological responses
}

\author{
Brenda Reyes-Sotelo $^{a}$ | Daniel Mota-Rojas ${ }^{\mathrm{b} *}$ (iD) | Julio Martínez-Burnes ${ }^{c}$ (iD) | \\ Adriana Olmos-Hernández $^{\mathrm{d}}$ (iD) | Ismael Hernández-Ávalos ${ }^{\mathrm{e}}$ (D) | Nancy José ${ }^{\mathrm{b}}$ | \\ Alejandro Casas-Alvarado ${ }^{\mathrm{b}}$ | Jocelyn Gómez ${ }^{\mathrm{b}}$ | Patricia Mora-Medina
}

aMaster in Science Program "Maestría en Ciencias Agropecuarias", Universidad Autónoma Metropolitana, Xochimilco Campus, Mexico City, Mexico.

${ }^{b}$ Neurophysiology, Behavior and Animal Welfare Assessment, DPAA, Universidad Autónoma Metropolitana (UAM), Mexico City, Mexico.

'Graduate and Research Department, Facultad de Medicina Veterinaria y Zootecnia, Universidad Autónoma de Tamaulipas, Victoria City, Tamaulipas, Mexico.

'Division of Biotechnology-Bioterio and Experimental Surgery, Instituto Nacional de Rehabilitación-Luis Guillermo Ibarra Ibarra (INR-LGII), Secretaría de Salud

(SSA), Mexico City, Mexico.

eClinical Pharmacology and Veterinary Anaesthesia, Department of Biological Science, FESC, Universidad Nacional Autónoma de México (UNAM), Mexico.

fDepartment of Livestock Sciences. Universidad Nacional Autónoma de México (UNAM), FESC, Mexico.

Corresponding author:dmota@correo.xoc.uam.mx

\begin{abstract}
Adaptation to extrauterine life brings about various changes, which initially are reflected in physiological alterations in the newborn puppy. Also, the newborn puppy's thermoregulating capacity is deficient, and many of the physiological processes for survival depend on this capacity. Severe modifications in body temperature can lead to hypothermia in a few hours. Hence, the first 24 to $72 \mathrm{~h}$ of life correspond to the highest risk time, in which the newborn can course with moderate to severe hypothermia because the shivering reflexes and vasoconstriction mechanisms are not yet developed in the newborn of this species. Temperature stabilization is reached up to the 18th day of age. However, the colostrum's adequate consumption could provide a high energy supply, contributing to a fast recovery of temperature and, consequently, to a high survival rate. This review aims to analyze the factors that affect thermoregulation of the newborn puppy, the physiological and behavioral responses, as well as to discuss the influence of the colostrum as an energy source and production of heat to face hypothermia, aside from discussing recent scientific findings of infrared thermography (IRT) used to assess the thermal response of the newborn puppy to cope with hypothermia.
\end{abstract}

Keywords cooling, hypothermia, neonatal care, puppy welfare, thermal biology, viability

\section{Introduction}

Mortality in the newborn puppy ranges from 5 to 35\%, and one of the leading causes is hypothermia (Münnich and Küchenmeister 2014), although its incidence is not reported and then is not well known. Therefore, thermoregulation becomes essential in the newborn puppy because it is deficient (Fitzgerald and Newquist 2011; Hull 1973); thus, the processes like hypothermia and hyperthermia develop fast (Harri et al 1991). Neonatal survival is tightly related to thermogenesis, especially when there is a significant reduction of the body temperature at the time of birth when passing from a warm environment in the uterus to an extrauterine environment (Nowak and Poindron 2006; Vannucchi et al. 2012); a change that impacts the newborn puppy because it lacks the shivering reflex and the vasoconstriction mechanisms, which are still under development (Indrebø et al. 2007; Nakamura and Morrison 2011).

The first 24 to $72 \mathrm{~h}$ after birth comprise the highest risk time for the temperature descent (Mullany et al. 2010), which can lead to systemic biochemical changes, such as hypoglycemia, hypoalbuminemia, energy alteration, that can trigger a delay in growth, an acid-base alteration, leading to multiple organ dysfunction (Lawler 2008). The ingestion of the colostrum could provide a $10 \%$ weight recovery during the first $24 \mathrm{~h}$ after birthand ensure the newborn puppy's survival.

On the other hand, there is scientific interest in the appropriate use of therapeutic hypothermia for pathological processes mainly in humans and, recently, in veterinary medicine (Brodeur et al 2017). This therapy is based on the reduction of the metabolic demand of the central nervous system (SNC) (Polderman 2009; Sinclair and Andrews 2010). For this reason, the objectives of this review are: to analyze the factors that affect the thermoregulation of the newborn puppy, its behavioral and physiological responses, to discuss the influence of the colostrum as an energy source and for the production of heat in the face of hypothermia, and to consider the recent scientific findings from the use of infrared thermography (IRT) to assess the thermal response to cope with hypothermia in the newborn puppy.

\section{Physiological response to hypothermia}

Thermoregulation in newborn mammals, both human and non-human, is deficient as compared to that of adults (Fitzgerald and Newquist 2011; Hull 1973; Mota-Rojas et al. 
2016, 2018; Bertoni et al. 2019; Casas-Alvarado et al. 2020) because the thermoneutral zone is narrow and depends on the type of stimulus for the processes of hypothermia and hyperthermia to develop (Harri et al. 1991; Mota-Rojas et al. 2019a,b; 2020; 2021a,b; Bertoni et al. 2020a,b). Temperatures below 36.5 ㅇ C are associated with hypothermia and an increase in mortality (Chitty and Wyllie 2013; Laptook et al. 2007; Martínez-Burnes et al. 2019; Villanueva-García et al 2021).

The newborn's normal rectal temperature ranges between 35 and $37^{\circ} \mathrm{C}$, increasing from $36.1^{\circ} \mathrm{C}$ to $37.8^{\circ} \mathrm{C}$ on the first day of age and reaching a self-regulation period on day 28 after birth (Wilborn 2018). However, just after birth, temperature diminishes, perhaps, as an adaptation measure, protecting against hypoxia and acidosis, reducing the metabolic demand (Lawler 2008; van der Weyden et al. 1986). It is then that hypothermia produces a decrease in the metabolic activity of tissues, like the central nervous system (SNC), with the subsequent diminution of the ionic exchange needs and, hence, of adenosine triphosphate (ATP) consumption. This reduction in the mitochondrial activity and the binding of decoupling proteins reduces the generation of reactive species without losing the transmembrane potentials and blocking the release of apoptogenic proteins (Lehtonen et al. 2017; Nuñez et al. 2018).

It must also be considered that the physiological functions are kept within the average temperature; however, if body temperature descends to 21.1 으, a drastic reduction of the cardiac rhythm to 40 beats per minute (bpm) and loss of the suction reflex can be observed (Fitzgerald and Newquist 2011). In turn, hypothermia is associated with an increase in the metabolic rate (Gandy et al. 1964), respiratory distress (Costeloe et al. 2012; Stephenson et al. 1970), diminished ingestion of colostrums, and low weight gain (Glass et al 1968), hypoglycemia (Lenclen et al. 2002; Mann and Elliott 1957; Mathur et al. 2005), and alterations of the acid-base equilibrium (Gandy et al. 1964); all changes lead to a multiple organ failure (Lawler 2008; Mota-Rojas et al. 2019a,b; 2020; 2021a,b).

Therefore, the first 24 to $72 \mathrm{~h}$ represent a higher risk of suffering moderate to severe hypothermia (Mullany et al. 2010). In lambs, Vannucchi et al. (2012) demonstrated that they can regulate their temperature during the first $60 \mathrm{~min}$ after birth, in contrast to calves and puppies. Thus, neonatal survival is related to thermogenesis (Mota-Rojas 1996, MotaRojas and Ramírez-Necoechea 1996; Nowak and Poindron, 2006; Vannucchi et al. 2012).

For these reasons, it is essential to maintain a controlled environmental temperature for the newborn puppy and provide an adequate temperature during the first week of life to prevent hypothermia. Also, avoid overheating which can trigger a dehydration process by respiratory failure due to reduced ventilatory response to carbon dioxide.

\section{Behavioral response to hypothermia}

All neonates can reduce their heat loss through behavioral adjustments like keeping together, searching for warm places, responding to the mother's call when they perceive cold, and maintaining quiet while being heated (Harri et al 1991; Hull 1973; Mota-Rojas et al 2016; 2018). The mother will separate the stillborn from the nest (Harri et al 1991). In altricial species, like the dog, which is immature at birth, stabilization of temperature is not reached until day 18 of age (Pineda and Dooley 2008).

In dog neonates, the shivering reflexes and the vasoconstriction mechanisms are not developed; hence, they are inefficient to compensate for the heat loss (Indreb $\varnothing$ et al. 2007). However, if the temperature is in the thermoneutral zone, they will not vocalize and keep quiet or sleeping, as occurs in other species when perceiving a warm temperature (Welker 1959; Harri et al. 1991). In contrast, in cold environments, it has been observed that blue fox puppies tend to minimize heat loss through behavioral responses, maximizing the production of heat (metabolism). Heat is produced by metabolism, but its increase leads to a loss by increasing circulation, which generates heat transfer from the inside to the surface, triggering a more significant heat loss than that produced, leading to a faster cooling (Harri et al. 1991).

For the dog, it has been argued that the adopted mechanism is the same because thermogenesis with shivering is low or absent, as can be observed in Figure 1, resulting in a higher predisposition to develop hypothermia. Dog puppies have only $1.3 \%$ of body fat (Kienzle et al. 1998); hence, it could be that they primarily use the production of heat using non-shivering thermogenesis; thus, eating could be their only option for thermogenesis (Mila et al. 2015).

The puppy develops both behavioral and physiological strategies to avoid losing heat or, if already lost, to generate heat. Among the behavioral responses is the development of postures like the ball-like posture and huddling with congeners to reduce the body surface exposure to the environment and, keep body heat. Among the behavioral strategies developed to produce body-heat are increased energetic food consumption (Terrien et al. 2011). Regarding the physiological strategies, the puppy can start peripheral vasoconstriction and thermogenesis responses with or without shivering, although it has been described that puppies can only execute this response at 6 to 8 days of age (Lourenço and Machado 2013).

\section{Factors that influence thermoregulation in the newborn}

Diverse factors can be related to the thermoregulation of the newborn; in humans, for example, the maturation of the skin, the presence, and distribution of subcutaneous fat, genetic, ethnic, and metabolic factors can affect the thermal balance in a specific way in premature babies (Heimann et al 2013). In contrast, in mammals, like the dog, Johnson et al (2006) observed that the hair plays an essential role according to its consistency; thin hair diminishes the loss of heat from the skin, whereas the color of the hair, in the case of dark colors, tends to absorb more heat. In contrast, dogs with poor hair or absence have a lower capacity to retain heat or tolerate cold temperatures. It must be noted that smaller 
dogs tend to lose heat faster due to greater surface area to volume ratios (Rigotti et al 2015). For this reason, the temperature of the environment where the puppies are housed can have a negative or positive effect on their wellbeing (Jordan et al 2016); moisture, for example, must be kept at levels between 30 and $70 \%$ but maintaining sufficient ventilation to reduce foul smells, high ammonia levels, controlled air currents and moisture condensation (USDA 2013).

\section{Behavioral}

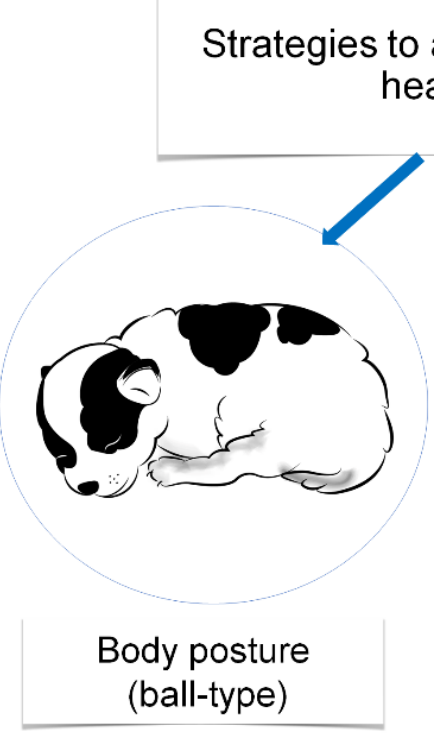

Responses to the activation of thermogenesis $\rightarrow$ Physiological

\section{Strategies to maintain body temperature} (heat)

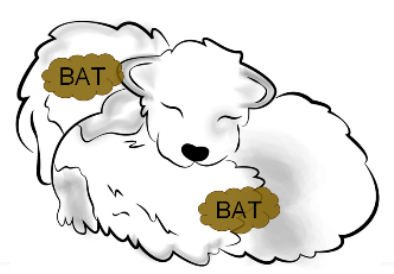

Shivering thermogenesis, although it has been described that puppies can only execute this response at 6 to 8 days of age

Huddling

Strategies to increase body heat production

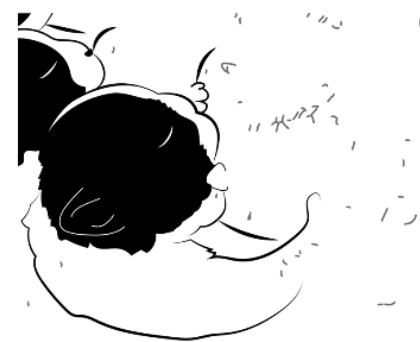

\section{Adequate ingestion of colostrum provides the newborn a high supply of energy}

BAT=Brown Adipose Tissue

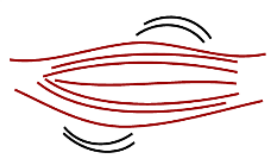

Shivering reflexes

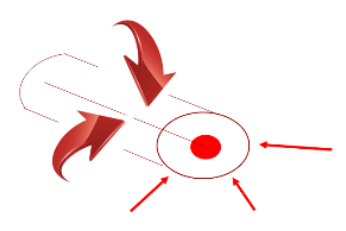

Peripheral vasoconstriction

Figure 1 Routes to avoid heat loss in the newborn puppy.

Figure 2 depicts the remainder factors that influence the thermoregulation of the newborn puppy.

Among the factors that influence the thermoregulation of the puppy are the consumption of colostrum, the body weight at birth, the environmental temperature, and even the breed; the body weight and the growth rate are important variables for the progressive increase of body temperature in puppies (Piccione et al 2010).

On the other side, Piccione et al (2009) observed that the daily oscillation of body temperature is weaker in the newborn and increases as the animal grows. This also changes according to the breed. These authors included 19 breeds; none of them exhibited significant temperature rhythmicity after birth, which reached a stable level at 6 weeks of age. Additionally, the difference between the morning and evening temperatures was noted for the first time on day 9 and increased gradually until reaching a stable daily rhythm at about 8 weeks after birth (Piccione et al 2010).

\subsection{Heat loss due to evaporation in the wet newborn puppy}

Dog neonates have a lower temperature than adults; in the first week of life, the rectal temperature ranges 
between 35 and $36 \circ \mathrm{C}$, reaching $36-38 \circ \mathrm{C}$ in the following weeks and, finally, at the time of weaning, temperatures become equal to that of adult dogs (Fitzgerald and Newquist 2011). The thermoregulating capacity is deficient, and the newborn's heat losses occur through conduction, convection, evaporation, and radiation processes (Knobel-Dail et al 2017), as can be observed in Figure 3. The most frequent are convection and evaporation, leading to heat production and developing peripheral vasoconstriction to avoid more heat loss (Adamson and Towell 1965).

After birth, puppies face a lower environmental temperature than that prevailing in the intrauterine environment and start losing heat through evaporation, conduction, radiation, and convection. The heat loss through evaporation occurs due to amniotic fluid on the newborns' surface; besides being in contact with cold surfaces, like metal tables, they lose heat through conduction. Newborn puppies also lose heat through radiation by emitting heat in electromagnetic waves, especially if they are in a cold environment. Likewise, moisture and wind produce heat loss through convection (Smith 2012).

In adult dogs, heat loss by evaporation through panting is the most important (Sessler 2000). Together with this, the coating acts as an isolator trapping the air against the skin because the latter possesses a low thermal conductivity (Randall et al 2002). However, in the case of wet coats, this isolation process is not efficient because water by having a high thermal conductivity leads to the development of more hypothermia, together with other factors, such as the diminished body fat, age, disease, or lack of acclimation (Mallet 2002; Oncken et al 2001; Sugano 1981), as occurs in newborns when diminishing their heat production (Armstrong et al 2005).

In a preliminary study of eutocic and dystocic deliveries in dogs, published by the authors of this work, the temperatures were recorded in diverse body regions in the wet puppy immediately after birth, observing differences among them; despite being wet, the puppy presents high temperatures due to the heat kept by the amniotic fluid that covers it, as can be seen in Figure 4.

For this reason, drying the newborn immediately after birth is basic and elemental in the handling of the newborn, reducing the heat losses due to evaporation, and providing controlled environmental conditions to promote a better adaptation and reducing mortality.

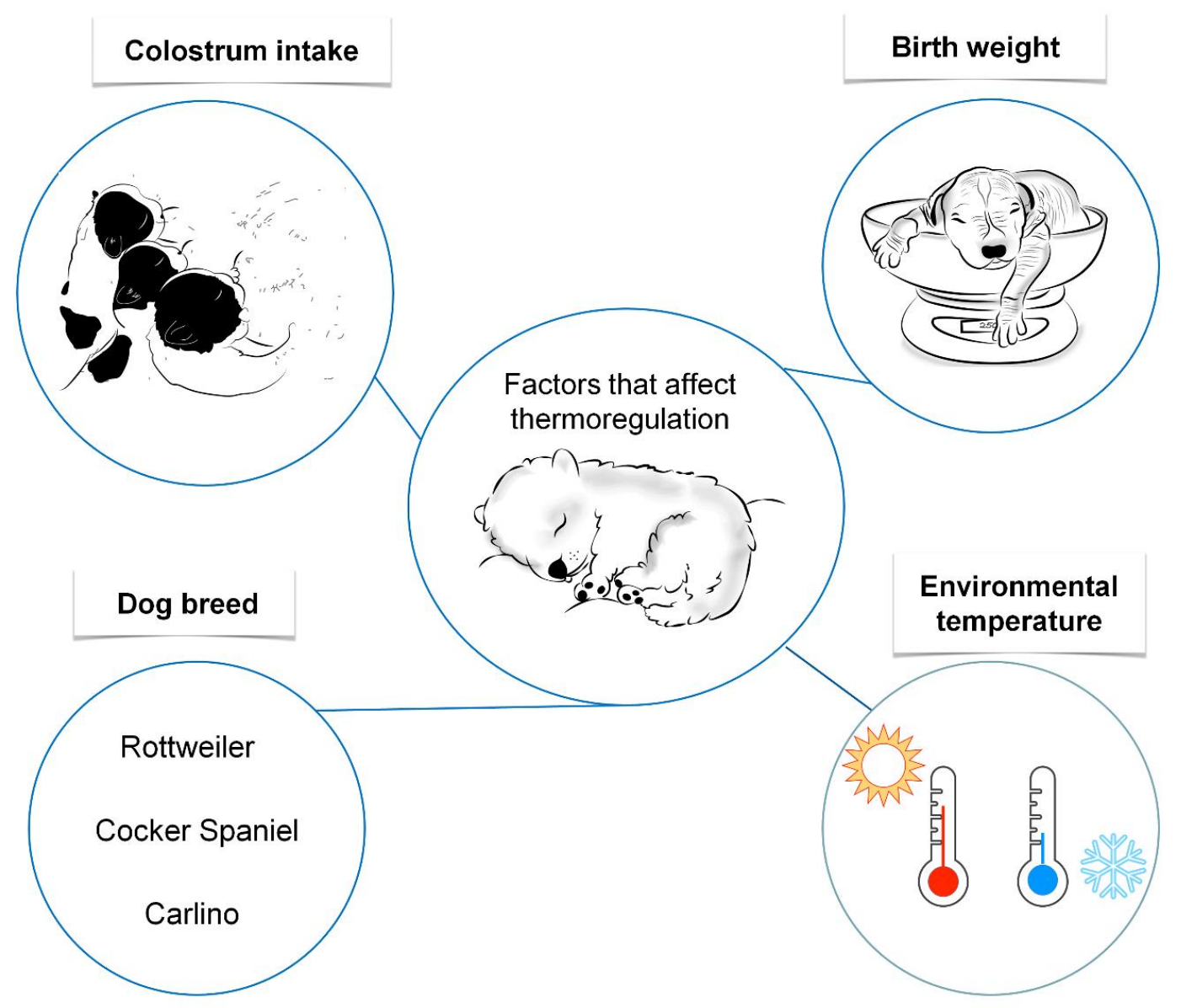

Figure 2 Factors that influence the thermoregulation of the newborn puppy. 


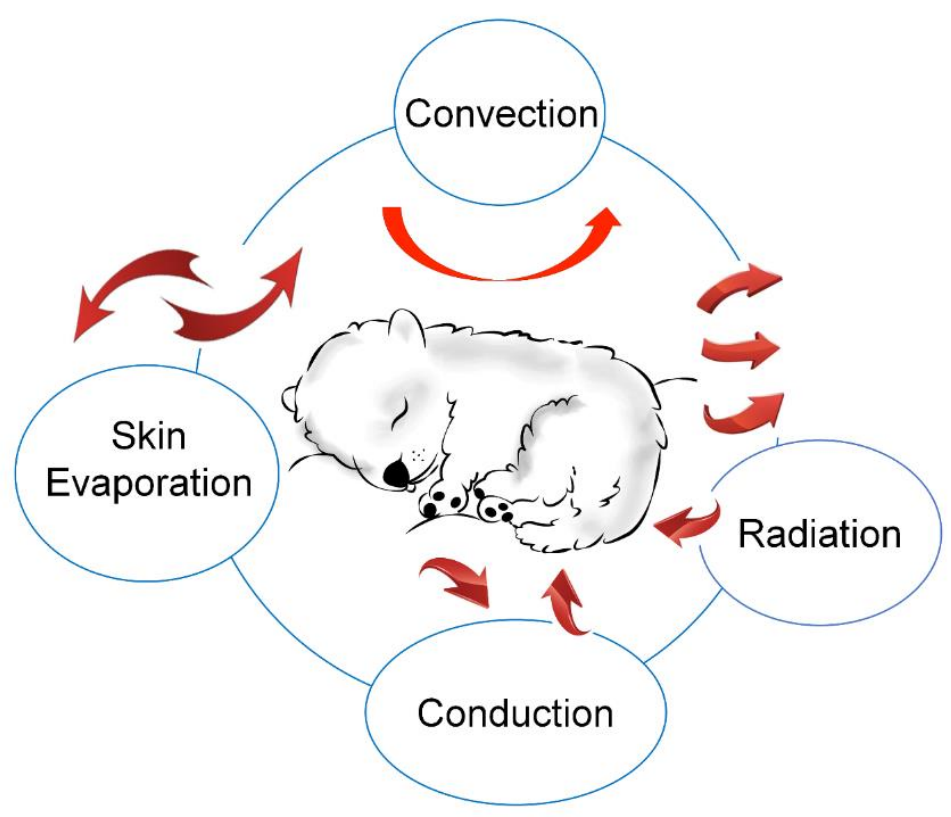

Figure 3 External mechanisms of heat loss in the newborn puppy.

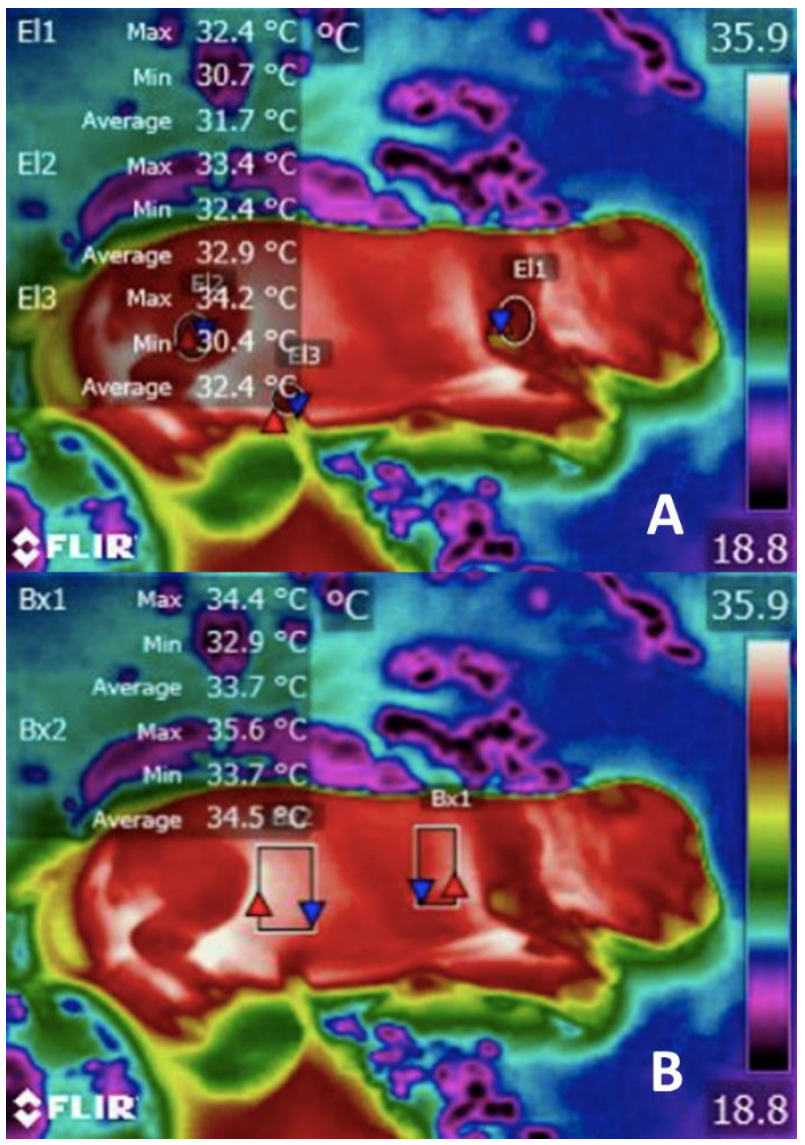

Figure 4 Changes in the vascular microcirculation observed with infrared thermography (IRT) in the newborn puppy wet with amniotic fluid, without colostrum, identified in different body regions. A) Forelimb (thoracic member). (El1) possess a minimal temperature of $30.7^{\circ} \mathrm{C}$ and maximal $32.4{ }^{\circ} \mathrm{C}$. Hind limb (Pelvic member) (El2) with a minimum temperature of $32.4{ }^{\circ} \mathrm{C}$ and a maximal of $33.4{ }^{\circ} \mathrm{C}$, which are $1.7{ }^{\circ} \mathrm{C}$ and 1 ${ }^{\circ} \mathrm{C}$ higher than those of the thoracic extremities. Umbilical cord insertion (E13) indicates a minimal temperature of $30.4^{\circ} \mathrm{C}$ and a maximal of $34.2^{\circ} \mathrm{C}$; the umbilical cord has not been clamped yet. B) Thoracic region (Bx1) shows a minimal temperature of $32.9^{\circ} \mathrm{C}$ and maximal of 34.4 ${ }^{\circ} \mathrm{C}$, which are just below the minimal normal rectal temperature of the newborn puppy $\left(35^{\circ} \mathrm{C}\right)$. Abdominal region (Bx2) reveals a minimal temperature of $33.7^{\circ} \mathrm{C}$ and maximal of $35.6^{\circ} \mathrm{C}$; being $0.8^{\circ} \mathrm{C}$ and $1.2^{\circ} \mathrm{C}$ higher in this region than in the thoracic region. 
4.2. The relation between hypothermia and vitality of the puppy

The degree and distribution of postnatal hypothermia are negatively correlated with survival (Tuchscherer et al 2000). In human medicine, the Apgar system, used since the '50s, assesses the neonatal viability level at $5 \mathrm{~min}$ after birth (Finster and Wood 2005) and is used as a predictor of mortality (Casey et al 2001). This system in veterinary medicine has been adapted to the characteristics of diverse species, foal, calf, piglets, and, recently, puppies. The five parameters to evaluate vitality in the newborn puppy are the color of mucosal membrane, cardiac rhythm, irritability reflex, mobility, respiratory frequency, obtaining from 0 to 2 points to reach a total of 10 points. It has been demonstrated that scores below 6 total points, when monitoring during the first 5 min of life, result in increased mortality indices in the first $24 \mathrm{~h}$ of life (Veronesi et al 2009). Currently it is known to be useful in the determination of mortality during the first 8 $\mathrm{h}$ of life, as demonstrated by Mila et al (2017), they assessed 367 newborn puppies from 66 different-sized bitches, the observation covered from $10 \mathrm{~min}$ to $8 \mathrm{~h}$ post-birth recordings of the Apgar score, glucose, lactate, beta-hydroxybutyrate, rectal temperature, and urinary gravity. A second recording was performed at $24 \mathrm{~h}$ after that, except for Apgar score and weight. Finally, mortality from birth to 21 days of age was monitored. They found that the Apgar score was influenced by the weight at birth $(P<0.001)$ and that during the first 24 $h$, only glucose could be associated with high mortality risk ( $P$ $<0.001$ ). It should be noted that the increase in weight was associated with an increase in rectal temperature on the first day of birth $(P<0.001)$. A possible explanation is that an insufficient brown adipose tissue (BAT) originates a fast decrement of glucagon and limited hepatic activity. Therefore, being the ingestion of the colostrum the only energy source leads to the diminution of temperature, which in turn, will be responsible for causing a low suction that will reflect in reduced ingestion of colostrum and, in consequence, of energy, with the possible risk of septicemia (Münnich and Küchenmeister 2014). For this reason, Groppetti et al (2010) consider evaluating suction and vocalization as additional parameters.

It is important to emphasize that the vitality scale differs in the canine species, due to brachycephalic breeds. However, the Apgar score is a method that allows evaluating the newborn puppy in the first minutes of life, and helps to identify those puppies that might require emergency medical care.

\subsection{Weight at birth (muscle mass and glycogen energy reserves)}

Bodyweight is one of the most important factors that influence cooling down, as observed in foxes, where the body mass index (BMI) determined the thermoregulating capacity of the offspring (Harri et al 1991). However, it must be taken into account that the weight at birth is correlated with the maternal weight and represents in average between 1 and
$3 \%$ of the body weight of the bitch (Trangerud et al 2007); likewise, the size of the clutch is associated with a low birth weight (Mila et al 2015). Indreb $\varnothing$ et al (2007) observed, in 744 puppies, that low birth weight and agalactia were the most frequent causes of death during the first 3 days after birth. Therefore, the bodyweight daily recording allows monitoring the average $8 \%$ increase during the first 3 days and $12 \%$ during the following 4 days.

For these reasons, maintaining a temperature and adequate glucose levels is limited in the newborn puppy (Allen et al 1966). Hence, hypothermia and hypoglycemia can trigger fatal consequences (Münnich and Küchenmeister 2014). Because neonates are unable to use the glycogen reserves and cannot maintain adequate levels of glucose in blood without constant feeding; it is so, that competing with its clutch for the nipple or colostrum at birth can bring about serious repercussions, initially of dehydration (Wilborn 2018) that later on will impact the neonatal survival (Groppetti et al 2015; Schrack et al 2017).

Some peripartum complications that predispose to hypoglycemia are a placental failure, premature birth, hypoxia, hypogalactia or agalactia, and adverse environmental conditions (Lawler, 2008). Hence, glucose and lack of oxygen lead to a fast deterioration of the energetic reserves and, in a short time, to tissue death (Nuñez et al 2018).

\subsection{Colostrum intake}

Animals that are born healthy develop the suction reflex within the first hour of life; hence, the colostrum intake provides the newborn not only a recovery of $10 \%$ of the lost body during the first $24 \mathrm{~h}$ after birth but also immunity during the first weeks and, aside from adequate nutrition, it enables the puppy to produce heat (Fitzgerald and Newquist 2011). Although, according to Kammersgaard et al (2011), the first suction only stimulates the displacement capacity of newborn piglets to reach a good position for nursing during the first two hours after birth, and thermoregulation is not entirely successful in this period. In the newborn puppy, colostrum effects can be observed in Figure 5, assessed from the moment of birth until $60 \mathrm{~min}$ post-colostrum, using different thermal windows.

In turn, Mila et al (2014) observed a total of 532 newborn puppies from 100 bitches in a controlled temperature $\left(28\right.$ and $\left.30{ }^{\circ} \mathrm{C}\right)$ environment at the floor level and without any other intervention. They determined that the birth weight is not correlated with mortality between day 2 and day 21 of age, but rather with the growth rhythm, which is due to the adequate ingestion of colostrum and its supply (First Day of lactation: $548 \mathrm{~kJ} / 100 \mathrm{~g}$ and immunoglobulin $\mathrm{G}(\operatorname{IgG}): 19.4 \mathrm{G} / \mathrm{L})$. They stated that adequate ingestion of colostrum provides the newborn a high supply of energy, which contributes to a fast recovery of the temperature lost at the time of birth and, concomitantly, its immature thermoregulation to avoid hypothermia (Dwyer and Morgan 2006). The colostrum supply contributes to the correct maturation and function of the gastrointestinal 
system, including nutrients absorption, as demonstrated in dogs, pigs, and calves (Bühler et al 1998; Burrin et al 1992; Schwarz and Heird 1994), diminishing the mortality indices.

However, the newborn puppy can have difficulties localizing the breast, leading to a delayed colostrum intake (Arteaga et al 2013). Hence, as demonstrated by ReyesSotelo (2020), once the newborn has nursed on colostrum, monitoring the different body regions is of vital importance to ensure temperature recovery by the newborn because, as shown in Figure 6, at 5 min post-colostrum, low temperatures are still observed, which require the establishment of protocols to increase the temperature of the puppy. Based on the aforementioned, Lawler (2008) suggests specific measures that will ensure the colostrum intake, such as reducing the excessive noise and maternal activity, help the puppy to nurse colostrum several times per day, maintain an adequate environmental temperature in the maternity areas or wherever the bitch gave birth, as well as favorable hygiene conditions, monitoring the weight gain of the newborn and its activity.
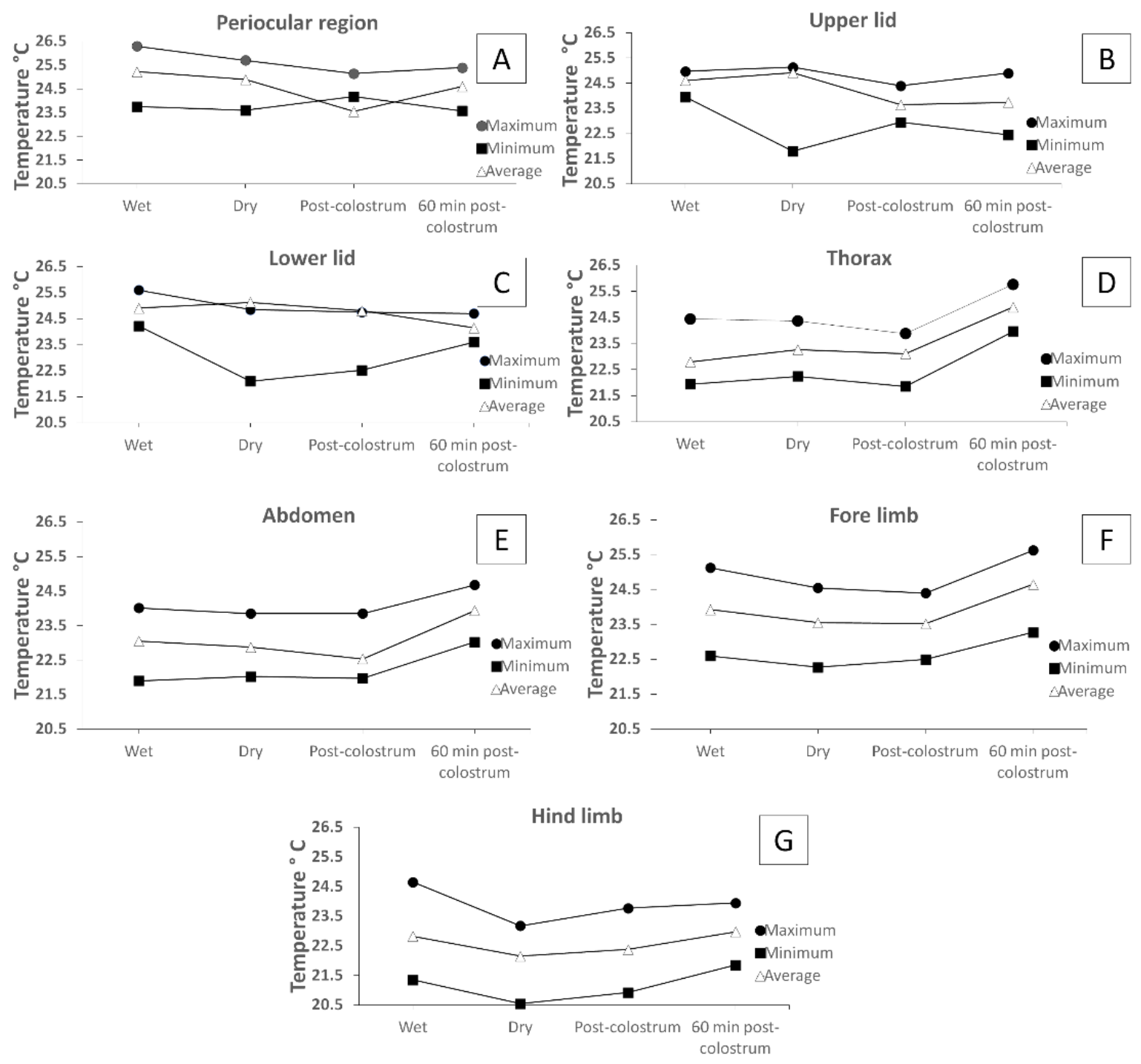

Figure 5 The maximal, minimal, and average temperature of the newborn puppy's thermal windows under four stages: wet, dry, postcolostrum, and $60 \mathrm{~min}$ post-colostrum. A) Temperature expressed in the Periocular region, indicates a minimum temperature of $23.7^{\circ} \mathrm{C}$ and a marked increase of $0.47^{\circ} \mathrm{C}\left(24.17^{\circ} \mathrm{C}\right)$. B) Upper lid. Note the temperature's behavior, the wet newborn evidence a minimal temperature of $32.9^{\circ} \mathrm{C}$, which tends to diminish $2.13^{\circ} \mathrm{C}$ when dry; after that, the puppy raises the temperature to $1.15^{\circ} \mathrm{C}$ during the post-colostrum stage, and tends to diminish $0.5^{\circ} \mathrm{C}$ during the 60 -min post-colostrum. C) Lower lid. Observe the temperature in the wet puppy $\left(24.2^{\circ} \mathrm{C}\right)$, which continues to diminish $2.1^{\circ} \mathrm{C}$ when being dry; it increases $0.4^{\circ} \mathrm{C}$ in the post-colostrum stage and keeps increasing up to $1.1^{\circ} \mathrm{C}$ at 60 min postcolostrum. D) Thorax. The minimal temperature expressed by remaining wet is of $21.9{ }^{\circ} \mathrm{C}$, it increases slightly in $0.34{ }^{\circ} \mathrm{C}$ when dry, and diminishes $0.39^{\circ} \mathrm{C}$ in the post-colostrum; at 60 min post-colostrum, the temperature increases consecutively exceeding even the temperature exhibited while being wet $\left(23.27\right.$ vs. $\left.22.6^{\circ} \mathrm{C}\right)$. E) Abdomen. It exhibits a minimum temperature of $21.9^{\circ} \mathrm{C}$ by remaining wet, $22.05^{\circ} \mathrm{C}$ when dry, followed by $21.9{ }^{\circ} \mathrm{C}$ at post-colostrum, and an evident $1.12{ }^{\circ} \mathrm{C}$ increase at 60 min post-colostrum. F) Fore limb (thoracic member). It expresses a minimal temperature of $22.6^{\circ} \mathrm{C}$ when wet, maintaining a temperature of $22.27{ }^{\circ} \mathrm{C}$ and $22.5^{\circ} \mathrm{C}$ when dry and post-colostrum, respectively, which increases $0.77{ }^{\circ} \mathrm{C}$ at $60 \mathrm{~min}$ post-colostrum. G) Hind limb (Pelvic member). Note the $0.8^{\circ} \mathrm{C}$ descent in the minimal temperature from wet to dry, keeping a temperature of $20.9^{\circ} \mathrm{C}$ post-colostrum; its temperature continues increases almost $1{ }^{\circ} \mathrm{C}\left(\right.$ i.e., $0.95{ }^{\circ} \mathrm{C}$ ). 


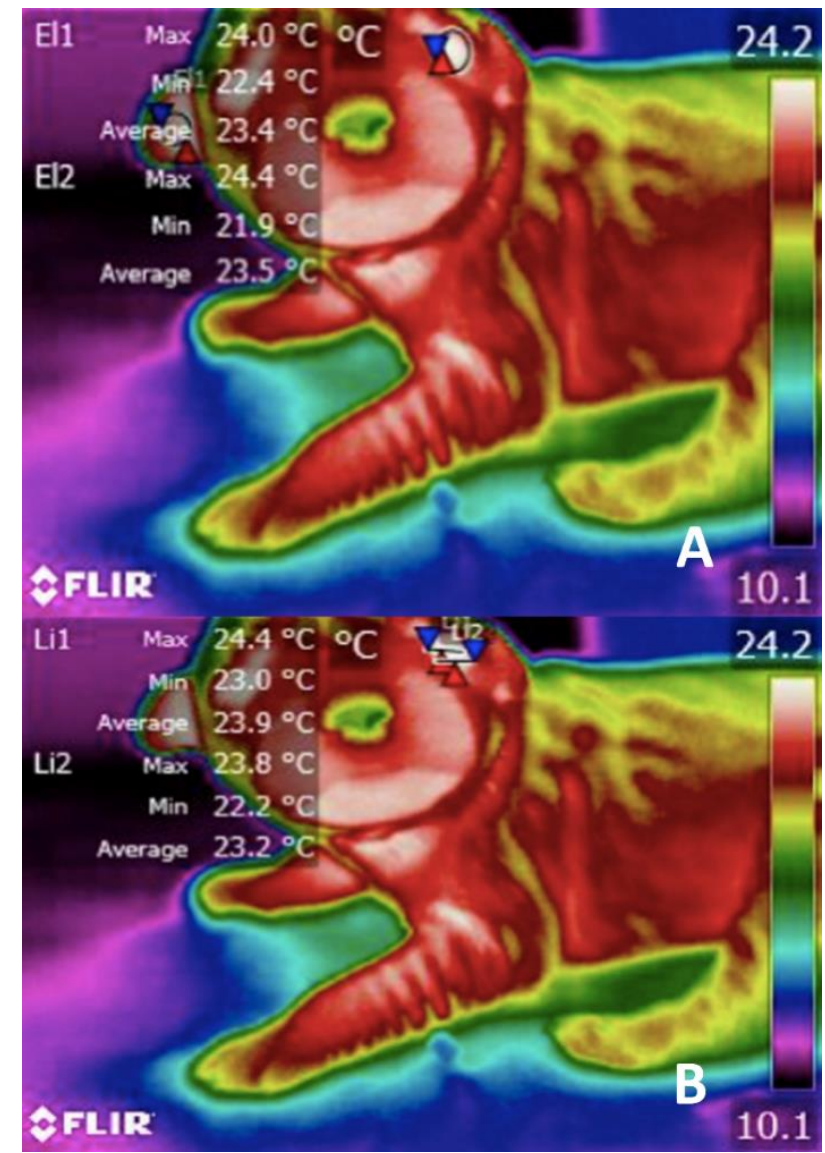

Figure 6 Effect of colostrum ( 5 min post-colostrum) on the dry newborn puppy's microcirculatory thermal changes in four different body regions. A) Ear canal (ellipse El1). Presents an average temperature of $23.4^{\circ} \mathrm{C}$. Periocular region limited by an ellipse (El2), the recording is on average of $23.5^{\circ} \mathrm{C}$; hence, compared with the auditory canal, there is a $0.1^{\circ} \mathrm{C}$ ascending variation. B) Upper lid, traced with an independent line (Li1) with an approximate length of $2 \mathrm{~cm}$, depicts an average temperature of $23.9^{\circ} \mathrm{C}$, which is higher than the two previous ones $\left(0.5^{\circ} \mathrm{C}\right.$ and $0.4{ }^{\circ} \mathrm{C}$, respectively). The lower lid, traced with an independent line (Li2) of $2 \mathrm{~cm}$, depicts a lower average temperature of $23.2^{\circ} \mathrm{C}\left(0.3{ }^{\circ} \mathrm{C}\right.$ below the periocular); despite having been nursed on colostrum, and where a more significant heat loss is evidenced. Maximal temperature is indicated with a red triangle and the minimal with a blue triangle.

Likewise, monitoring the minimal body temperature with the use of IRT could provide valuable information in a non-invasive way through the different thermal windows to be able, in the future, to determine the ideal regions for newborn monitoring. Figure 7 depicts IRT data derived from preliminary studies in puppies performed by the present authors, showing a newborn puppy from a eutocic whelping.

On the other hand, the clutch's handling must be adequate because the newborn puppy's immaturity of the newborn puppy makes it vulnerable to a high mortality rate on the first days. Evaluation of their performance at birth allows identifying those newborns that require additional support to that provided by the mother, which could increase this species' survival of this species.

\section{Thermographic findings in the hypothermia model of the newborn}

The incidence of hypothermia in veterinary medicine patients is still unknown; however, it is known that despite advances many unknowns have still to be resolved to be able to introduce techniques for its treatment. In the last years, therapeutic hypothermia has been appropriately introduced for disease processes in humans and veterinary medicine (Brodeur et al 2017), focusing on reducing the metabolic demand (Polderman 2009; Sinclair and Andrews 2010). The therapy involves three stages for its application: induction, maintenance, and rewarming (Polderman and Herold 2009); however, despite the efforts, each stage is associated with certain complications, like, for example, hypoalbuminemia when inducing low temperatures as well as electrolytic alterations. On the other hand, in veterinary medicine, its use in small breeds has been successful with a $90 \%$ survival in surgical processes, where induction of low temperatures is low and for less time, as reported by Moon and Ilkiw (1993).

For these reasons, monitoring with IRT the first minutes of life could help modify the care protocols of temperature and instrument integrated monitoring of diverse physiological processes (Abbas and Leonhardt 2014; Buddharaju et al 2007). It is to be remembered that when talking of evaluating the animal's welfare in veterinary medicine, this implies not just a continuous follow-up of its vital parameters but also monitoring of its emotional state and locomotion capacity (Vainer 2018), mechanisms that can 
be observed and assessed through a non-invasive method as is IRT.

There is still a long way to clarify the mechanisms that could help reduce neurological alterations, more studies are needed to understand the disease processes, hence, it is important to innovate and incorporate adequate techniques.

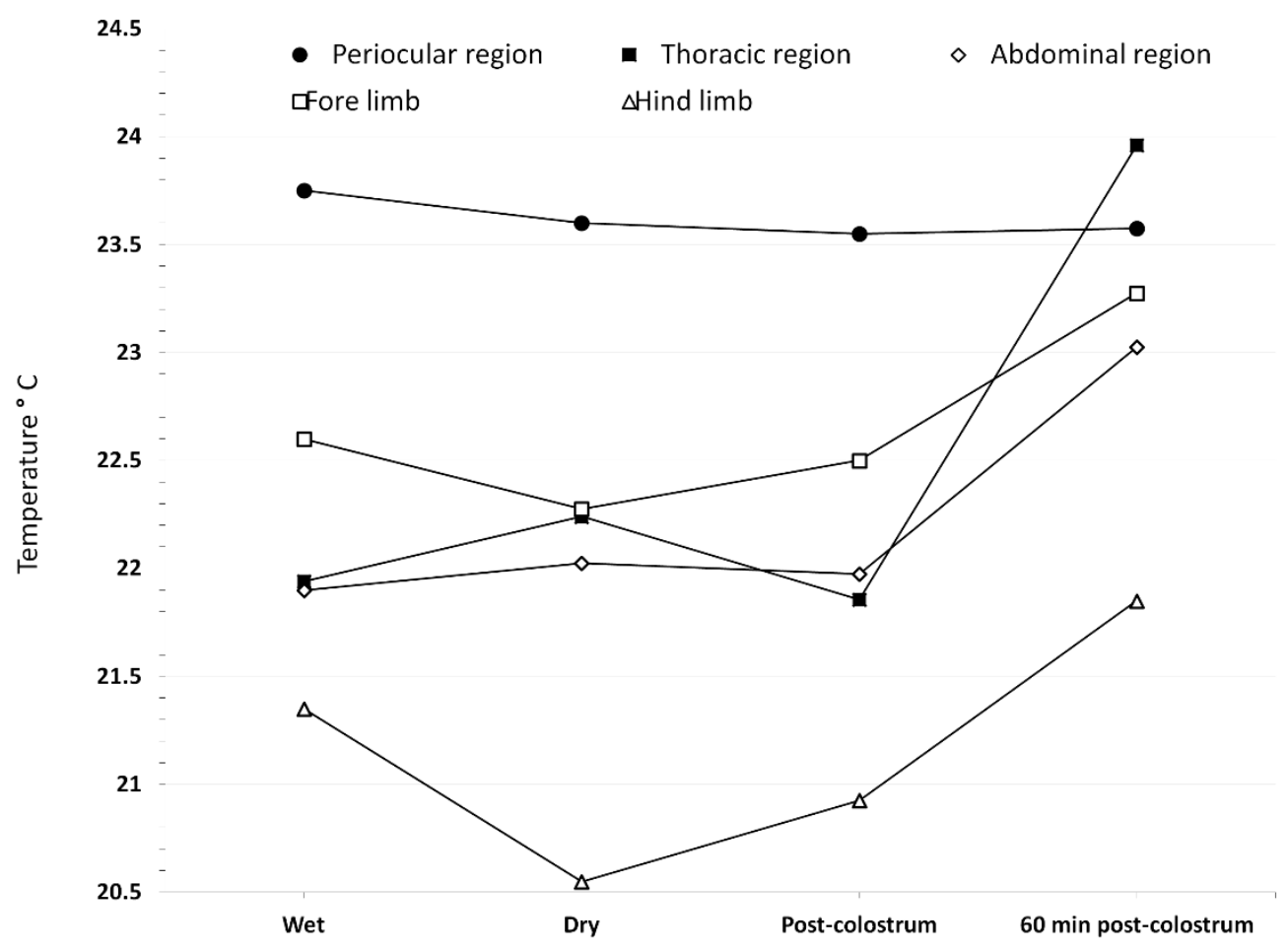

Figure 7 Minimal temperature expressed by the newborn puppy: wet, dry, post-colostrum, and 60 min post-colostrum. Note the temperature of the puppy wet with amniotic fluid in the abdominal and thoracic regions with $21.9{ }^{\circ} \mathrm{C}$. When the puppy is dry, the temperature increases by $0.34^{\circ} \mathrm{C}$ in the thorax and $0.152^{\circ} \mathrm{C}$ in the abdominal region; diminishing $0.39^{\circ} \mathrm{C}$ in the thorax regions and $0.05^{\circ} \mathrm{C}$ in the abdominal region in the post-colostrum stage. Finally, 60 -min post-colostrum, there are considerable increments of $2.11^{\circ} \mathrm{C}$ in the thoracic region and $1.05^{\circ} \mathrm{C}$ in the abdominal region. Regarding the anterior and posterior extremities, these present a temperature of $22.6^{\circ} \mathrm{C}$ and $21.35^{\circ} \mathrm{C}$, respectively, which diminishes $0.3^{\circ} \mathrm{C}$ in the anterior extremity and $0.89^{\circ} \mathrm{C}$ in the posterior. However, there is an increase of $0.23^{\circ} \mathrm{C}$ for anterior extremities and of $0.35^{\circ} \mathrm{C}$ for the posterior. Finally, both regions evidence an increase in temperature of $0.77^{\circ} \mathrm{C}$ and $0.93^{\circ} \mathrm{C}$, respectively, at $60 \mathrm{~min}$ post-colostrum. The periocular region shows $23.75^{\circ} \mathrm{C}$ in the wet puppy; afterward, the temperature varies slightly, with $23.6^{\circ} \mathrm{C}$ in the dry puppy, $23.55^{\circ} \mathrm{C}$ in the post-colostrum, and $23.57^{\circ} \mathrm{C}$ in the 60 -min post-colostrum.

\section{Final Considerations}

Thermoregulation in an altricial species, as the newborn puppy, differs from that of other species of which registries are available. Their morphological variability implies that the characteristics exhibited at birth are different even within the same species, making it difficult to establish the same handling and care protocols. The information available up to now on their low thermoregulating capacity due to the low percentage of brown fat tissue should become a guideline to establish additional handling of the environmental conditions surrounding the newborn, leading to achieving an increase in the survival indices.

In turn, the mechanisms known to generate a heat gain, like the shivering reflex and the vasoconstriction mechanisms, are not observed in this species or are not fully developed until day 18 of life. Hence, the losses due to hypothermia can be high if not detected in time.

Additionally, it must be pointed out that not only the previously mentioned factors influence thermoregulation, since the breed, but birth weight, environmental conditions, and colostrum intake could also be involved in the loss of newborn puppies during the first week of life due to hypothermia.

Specifically, the heat lost due to evaporation is translated into higher mortality in the post-partum stage because the puppy at the time of birth is wet; rapidly, the effect of air currents, prevailing in the facilities, and without an immediate drying of the newborn, will accelerate the cooling of the newborn. This can cause a temperature descent that will trigger a severe hypothermia if not cared for in time. 
All these factors as a whole could modify the vitality at birth, including alterations due to hypothermia, like low cardiac frequency, deficient inspiratory effort, and low motility translated into an inferior displacement of the puppy to find food.

Based on the above mentioned, a reduced feeding and a low birth weight demerit the capacity of the puppy to survive because its glycogen reserves are insufficient. Hence the colostrum is the primary source of energetic supply in the first $24 \mathrm{~h}$ post-birth, ensuring the food and warranting the capacity to produce heat in less time and adequate nursing.

Infrared thermography is a non-invasive method used in diverse species to evaluate and monitor the temperature in diverse processes, for which the use of thermal windows has been established. However, for newborn puppies, information is extrapolated from other species to find a better option according to the needs. Hence, more research in this species during the first hours of life is needed, which are the useful thermal windows to establish the monitoring bases for particular processes, like hypothermia and its collateral effects, leading to diminishing the mortality indices to this complication.

Finally, it is important to point out that the dog serves as a model to study altricial species and is of vital relevance to establishing whether therapeutical hypothermia is useful in veterinary medicine as a protocol to handle and care for the alterations at birth that cause sequelae in the adult stage, like perinatal asphyxia.

\section{Conflict of Interest}

The authors declare that they have no conflict of interest.

\section{Funding}

This research did not receive any financial support.

\section{References}

Abbas AK, Leonhardt S (2014) Intelligent neonatal monitoring based on a virtual thermal sensor. BMC Medical Imaging 14: 9. doi: 10.1186/1471-234214-9

Adamson SK, Towell ME (1965) Thermal homeostasis in the fetus and newborn. Anesthesiology 26: 531-548. doi: 10.1097/00000542-19650700000017

Allen DT, Kornhauser D, Schwartz R (1966) Glucose homeostasis in the newborn puppy. American Journal of Diseases of Children 112: 343-350. doi:10.1001/archpedi.1966.02090130117011

Armstrong SR, Roberts BK, Aronsohn M (2005) Perioperative hypothermia. Journal of Veterinary Emergency and Critical Care doi: 10.1111/j.14764431.2005.04033.x

Arteaga L, Rödel HG, Elizalde MT, González D, Hudson R (2013) The pattern of nipple use before weaning among littermates of the domestic dog. Ethology 119:1. doi:10.1111/eth.12030

Bertoni A, Mota-Rojas D, Álvarez A, Napolitano F (2019) Chapter 14. Reproductive advances in river buffalo using infrared thermography. In Guerrero-Legarreta, I., Napolitano, F., Mota-Rojas, D., Orihuela, A. (Ed.). The river buffalo in the Americas ( $2^{\text {nd }}$. Ed.). Mexico. BM Editores press. pp. 461488.

Bertoni A, Napolitano F, Mota-Rojas D, Sabia E, Alvarez A, Mora P, Morales A, Berdugo J, Guerrero-Legarretra I (2020a) Similarities and differences between river buffaloes and cattle: health, physiological, behavioural and productivity aspects. Journal of Buffalo Science 9:92-109. DOI: https://doi.org/10.6000/1927-520X.2020.09.12

Bertoni A, Mota-Rojas D, Álvarez-Macias A, Mora-Medina P, GuerreroLegarreta I, Morales-Canela A, Gómez-Prado J, José-Pérez N, MartínezBurnes J (2020b) Scientific findings related to changes in vascular microcirculation using infrared thermography in the river buffalo. Journal of Animal Behaviour and Biometeorology 8:288-297. doi.org/10.31893/jabb.20038

Brodeur A, Wright A, Cortes Y (2017) Hypothermia and targeted temperature management in cats and dogs. Journal of Veterinary Emergency and Critical Care 27: 151-163. doi:10.1111/vec.12572

Buddharaju P, Pavlidis IT, Tsiamyrtzis P, Bazakos M (2007) Physiology-based face recognition in the thermal infrared spectrum. IEEE Transactions on Pattern Analysis and Machine Intelligence 29:613-626. doi:10.1109/TPAMI.2007.1007

Bühler C, Hammon H, Rossi GL, Blum JW (1998) Small Intestinal Morphology in Eight-Day-Old Calves Fed Colostrum for Different Durations or only Milk Replacer and Treated with Long-R3-Insulin-Like Growth Factor I and Growth Hormone. Journal of Animal Science 76: 758-765. doi:10.2527/1998.763758x

Burrin DG, Shulman RJ, Reeds PJ, Davis TA, Gravitt KR (1992) Porcine colostrum and milk stimulate visceral organ and skeletal muscle protein synthesis in neonatal piglets. Journal of Nutrition 122: 1205-1213. doi:10.1093/jn/122.6.1205

Casas-Alvarado A, Mota-Rojas D, Hernández-Ávalos I, Mora P, Olmos HA, Verduzco A, Reyes-Sotelo B, Martínez-Burnes J (2020) Advances in infrared thermography: Surgical aspects, vascular changes, and pain monitoring in veterinary medicine. Journal of Thermal Biology 92:102664. https://doi.org/10.1016/j.jtherbio.2020.102664

Casey BM, McIntire DD, Leveno KJ (2001) The continuing value of the Apgar score for the assessment of newborn infants. New England Journal of Medicine 344:467-471. doi:10.1056/NEJM200102153440701

Chitty H, Wyllie J (2013) Importance of maintaining the newly born temperature in the normal range from delivery to admission. In Seminars in Fetal and Neonatal Medicine 18: 362-368. doi:10.1016/j.siny.2013.08.002

Costeloe KL, Hennessy EM, Haider S, Stacey F, Marlow N, Draper ES (2012) Short term outcomes after extreme preterm birth in England: Comparison of two birth cohorts in 1995 and 2006 (the EPICure studies). BMJ (Online) 345:e7976. doi:10.1136/bmj.e7976

Dwyer CM, Morgan CA (2006) Maintenance of body temperature in the neonatal lamb: Effects of breed, birth weight, and litter size. Journal of Animal Science 84:1093-1101. doi:10.2527/2006.8451093x

Finster M, Wood M (2005) The Apgar score has survived the test of time. Anesthesiology 102:855-857. https://doi.org/10.1097/00000542200504000-00022

Fitzgerald KT, Newquist KL (2011) Husbandry of the Neonate. Small Animal Pediatrics doi:10.1016/B978-1-4160-4889-3.00006-1

Gandy GM, Adamson K, Cunningham N, Silverman WA, James LS (1964) Thermal Environment and acid-base homeostasis in human infants during the first few hours of life. The Journal of Clinical Investigation 43:751-758. doi:10.1172/JCI104959

Glass L, Silverman WA, Sinclair JC (1968) Effect of the thermal environment on cold resistance and growth of small infants after the first week of life. Pediatrics 41:1033-1046.

Groppetti D, Pecile A, Del Carro AP, Copley K, Minero M, Cremonesi F (2010) Evaluation of newborn canine viability by means of umbilical vein lactate measurement, apgar score and uterine tocodynamometry. Theriogenology 74:1187-1196. doi:10.1016/j.theriogenology.2010.05.020

Groppetti D, Ravasio G, Bronzo V, Pecile A (2015) The role of birth weight on litter size and mortality within $24 \mathrm{~h}$ of life in purebred dogs: What aspects are involved? Animal Reproduction Science 163: 112-119. doi:10.1016/j.anireprosci.2015.10.005

Harri M, Mononen J, Haapanen K, Korhonen H (1991) Postnatal changes in hypothermic response in farmborn blue foxes and raccoon dogs. Journal of Thermal Biology 16:71-76. doi:10.1016/0306-4565(91)90001-I 
Heimann K, Jergus K, Abbas AK, Heussen N, Leonhardt S, Orlikowsky T (2013) Infrared thermography for detailed registration of thermoregulation in premature infants. Journal of Perinatal Medicine41:613-620. doi:10.1515/jpm-2012-0239

Hull D (1973) Thermoregulation in young mammals. In Comparative Physiology of Thermoregulation. doi:10.1016/b978-0-12-747603-2.50010-2

Indreb $\varnothing$ A, Trangerud C, Moe L (2007) Canine neonatal mortality in four large breeds. Acta Veterinaria Scandinavica 49: 1-5. doi:10.1186/1751-0147-49S1-S2

Johnson SI, McMichael M, White G (2006) Heatstroke in small animal medicine: A clinical practice review. Journal of Veterinary Emergency and Critical Care doi:10.1111/j.1476-4431.2006.00191.x

Jordan M, Bauer AE, Stella JL, Croney C (2016) Temperature Requirements for dogs. Purdue Extention. https://www.extension.purdue.edu/extmedia/va/va-16-w.pdf Accessed November 13, 2020

Kammersgaard T, Pedersen LJ, Jørgensen E (2011) Hypothermia in neonatal piglets:Interactions and causes of individual defferences. Journal of Animal Science 89:2073-2085. doi: 10.2527/jas.2010-3022

Kienzle E, Zentek J, Meyer H (1998) Body composition of puppies and young dogs. Journal of Nutrition 128: 2680S-2683S. doi:10.1093/jn/128.12.2680s

Knobel-Dail RB, Holditch-Davis D, Sloane R, Guenther BD, Katz LM (2017) Body temperature in premature infants during the first week of life: Exploration using infrared thermal imaging. Journal of Thermal Biology 69:118-123. doi.org/10.1016/j.jtherbio.2017.06.005

Laptook A, Salhab W, BB (2007) Admission temperature of low birth weight infants: Predictors and associated morbidities. Pediatrics 119: e643-e649. https://doi.org/10.1542/peds.2006-0943

Lawler DF (2008) Neonatal and pediatric care of the puppy and kitten. Theriogenology $70(3)$

384-392.

https://doi.org/10.1016/j.theriogenology.2008.04.019

Lehtonen L, Gimeno A, Parra-Llorca A, Vento M (2017) Early neonatal death A challenge worldwide. Seminars in Fetal and Neonatal Medicine 22: 153 160. doi:10.1016/j.siny.2017.02.006

Lenclen R, Mazraani M, Jugie $M$, Couderc S, Hoenn E, Carbajal R, Blanc $P$, Paupe A (2002) Utilisation d'un sac en polyéthylène: Un moyen d'améliorer l'environnement thermique du prématuré en salle de naissance. Archives de Pediatrie 9: 238-244. doi:10.1016/S0929-693X(01)00759-X

Lourenço MLG, Machado LH (2013) Características do período de transição fetal-neonatal e particularidades fisiológicas do neonato canino. Revista Brasileira de Reprodução Animal 37: 303-308.

Mallet ML (2002) Pathophysiology of accidental hypothermia. In QJM Monthly Journal of the Association of Physicians 95: 775-785. doi:10.1093/qjmed/95.12.775

Mann TP, Elliott RIK (1957) Neonatal cold injury due to accidental exposure to cold. The Lancet 269: 229-234. doi:10.1016/S0140-6736(57)90298-2

Martínez-Burnes J, Mota-Rojas D, Villanueva-García D, Ibarra-Rios D, Lezama-García K, Barrios-García H, López-Mayagoitia A (2019) Invited review: Meconium aspiration syndrome in mammals. CAB Reviews 14:1-12. doi: 10.1079/PAVSNNR201914013

Mathur N, Krishnamurthy S, Mishra T (2005) Evaluation of WHO classification of hypothermia in sick extramural neonates as predictor of fatality. Journal of Tropical Pediatrics 51: 342-345

Mila H, Feugier A, Grellet A, Anne J, Gonnier M, Martin M, Rossig L, Chastant Maillard S (2014) Inadequate passive immune transfer in puppies: Definition, risk factors and prevention in a large multi-breed kennel. Preventive Veterinary Medicine 116: 209-213. doi:10.1016/j.prevetmed.2014.05.001

Mila H, Grellet A, Delebarre M, Mariani C, Feugier A, Chastant-Maillard, S. (2017) Monitoring of the newborn dog and prediction of neonatal mortality. Preventive Veterinary Medicine, 143: 11-20. doi:10.1016/j.prevetmed.2017.05.005

Mila H, Grellet A, Feugier A, Chastant-Maillard S (2015) Differential impact of birth weight and early growth on neonatal mortality in puppies 1,2 . Journal of Animal Science 93: 4436-4442. doi:10.2527/jas2015-8971

Moon PF, Ilkiw JE (1993) Surface-induced hypothermia in dogs: 19 cases
(1987-1989). Journal of the American Veterinary Medical Association 202: 437-444.

Mota-Rojas D (1996) Intensive therapy in the hypothermic newborns. Thesis. Universidad Autónoma Metropolitana p. 87.

Mota-Rojas D, Ramírez-Necoechea R (1996) Dead piglets and losses for the pig farmer. AgroNegocios 18:2-11

Mota-Rojas D, López A, Muns R, Mainau E, Martínez-Burnes J (2016) Chapter 5. Piglet welfare. In: Mota-Rojas D, Velarde-Calvo A, Huertas-Canen S, Cajíao MN (Eds) Animal Welfare, A Global Vision in Ibero-America]. Bienestar Animal una Visión Global en Iberoamérica, 3rd edn. Elsevier, Barcelona, pp. 51-62.

Mota-Rojas D, López A, Martínez-Burnes J, Muns R, Villanueva-García D, Mora-Medina P, González-Lozano $\mathrm{M}$, Olmos-Hernández A, RamírezNecoechea R (2018) Invited review: Is vitality assessment important in neonatal animals? CAB Reviews 13:1-13. doi: 10.1079/PAVSNNR13036

Mota-Rojas D, Napolitano F, Sarubbi J, Braghieri A, Martínez-Burnes J, Bertoni A, Ghezzi MD (2019a) Chapter 16. Thermal responses in river buffalo. In Guerrero-Legarreta, I., Napolitano, F., Mota-Rojas, D., Orihuela, A. (Ed.). The river buffalo in the Americas ( 2 nd. Ed.). Mexico. BM Editores press. pp. 512-538.

Mota-Rojas D, Napolitano F, González LM, Martínez-Burnes J, Braghieri A, López A, De la Rosa G, Orihuela A (2019b) Chapter 11. Identifying risk factors for buffalo dystocia and stillbirths. In Guerrero-Legarreta, I., Napolitano, F., Mota-Rojas, D., Orihuela, A. (Ed.). The river buffalo in the Americas ( $2^{\text {nd }}$. Ed.). Mexico. BM Editores press. pp. 357-379.

Mota-Rojas D, Broom DM, Orihuela A, Velarde A, Napolitano N, AlonsoSpilsbury M (2020) Effects of human-animal relationship on animal productivity and welfare. Journal of Animal Behaviour and Biometeorology 8:196-205. doi.org/10.31893/jabb.20026

Mota-Rojas D, Napolitano F, Braghieri A, Guerrero LI, Bertoni A, MartínezBurnes J, Gómez PJ, Barrios-García H, Pérez NJ, Álvarez-Macías A, MoraMedina P, Orihuela A (2021a) Thermal biology in river buffalo in the humid tropics: neurophysiological and behavioral responses. Journal of Animal Behaviour and Biometeorology 9: 2103. doi:10.31893/jabb.21003

Mota-Rojas D, Olmos-Hernández A, Verduzco-Mendoza A, Lecona-Butrón $H_{\text {, }}$ Martínez-Burnes J, Mora-Medina P, Gómez-Prado PJ, Orihuela A (2021b) Infrared thermal imaging associated with pain in laboratory animals. Experimental Animals 70: 20-0052. doi:10.1538/expanim.20-0052.

Mullany LC, Katz J, Khatry SK, LeClerq SC, Darmstadt GL, Tielsch JM (2010) Risk of mortality associated with neonatal hypothermia in southern Nepal. In Archives of Pediatrics and Adolescent Medicine 167: 650-656. doi:10.1001/archpediatrics.2010.103

Münnich A, Küchenmeister U (2014) Causes, diagnosis and therapy of common diseases in neonatal puppies in the first days of life: Cornerstones of practical approach. Reproduction in Domestic Animals 49: 64-74. doi:10.1111/rda.12329

Nakamura K, Morrison SF (2011) Central efferent pathways for colddefensive and febrile shivering. The Journal of Physiology 589: 3641-3658. doi:10.1113/jphysiol.2011.210047

Nowak R, Poindron P (2006) From birth to colostrum: Early steps leading to lamb survival. Reproduction Nutrition Development 46: 431-446. https://doi.org/10.1051/rnd:2006023

Nuñez A, Benavente I, Blanco D, Boix H, Cabañas F, Chaffanel M, FernándezColomer B, Fernández-Lorenzo JR, Loureiro B, Moral MT, Pavón A, Tofé I, Valverde E, Vento M (2018) Estrés oxidativo en la asfixia perinatal y la encefalopatía hipóxico-isquémica. Anales de Pediatría 88: 228.e1-228.e9. doi:10.1016/j.anpedi.2017.05.005

Oncken AK, Kirby R, Rudloff E (2001) Hypothermia in Critically III Dogs and Cats. Compendium on Continuing Education for the Practicing Veterinarian 23: 506-520.

Piccione G, Fazio F, Giudice E, Refinetti R (2009) Body size and the daily rhythm of body temperature in dogs. Journal of Thermal Biology 34: 171175. doi:10.1016/j.jtherbio.2009.01.004

Piccione G, Giudice E, Fazio F, Mortola JP (2010) The daily rhythm of body temperature, heart and respiratory rate in newborn dogs. Journal of Comparative Physiology B: Biochemical, Systemic, and Environmental 
Physiology 180: 895-904. https://doi.org/10.1007/s00360-010-0462-1

Pineda M, Dooley M (2008) McDonald's Veterinary Endocrinology and Reproduction (5th Edition). Wiley-Blackwell pp, 597.

Polderman KH (2009) Mechanisms of action, physiological effects, and complications of hypothermia. Critical Care Medicine 37:S186-202. doi:10.1097/CCM.0b013e3181aa5241

Polderman KH, Herold I (2009) Therapeutic hypothermia and controlled normothermia in the intensive care unit: Practical considerations, side effects, and cooling methods. In Critical Care Medicine 37: 1101-1120. doi: 10.1097/CCM.0b013e3181962ad5

Randall D, Burgreen W, French K (2002) Energetic costs of meeting environmental challenges. In D. Randall, W. Burgreen, K. French (Eds.), Animal Physiology 5th ed, WHFreeman and Co. pp. 699-736.

Reyes-Sotelo B (2020) Bienestar del cachorro neonato: Evaluación clínica, fisiológica y neurológica. Tesis de Maestria en Ciencias Agropecuarias. Universidad Autónoma Metropolitana. pp. 1-130.

Rigotti CF, Jolliffe CT, Leece EA (2015) Effect of prewarming on the body temperature of small dogs undergoing inhalation anesthesia. Journal of the American Veterinary Medical Association 247: 765-770. doi:10.2460/javma.247.7.765

Schrack J, Dolf G, Reichler IM, Schelling C (2017) Factors influencing litter size and puppy losses in the Entlebucher Mountain dog. Theriogenology 95: 163170. doi:10.1016/j.theriogenology.2017.03.004

Schwarz SM, Heird WC (1994) Effects of feeding on the small intestinal mucosa of beagle pups during the first $5 \mathrm{~d}$ of life. American Journal of Clinical Nutrition 60: 879-886. doi:10.1093/ajcn/60.6.879

Sessler DI (2000) Perioperative heat balance. Anesthesiology 92: 578 doi:10.1097/00000542-200002000-00042

Sinclair HL, Andrews PJD (2010) Bench-to-bedside review: Hypothermia in traumatic brain injury. Critical Care 14:204. doi:10.1186/cc8220

Smith J (2012) Temperature Measurement And Thermoregulation In The Term And preterm infant. Professional Doctorate (Research) thesis, James Cook University. http://eprints.jcu.edu.au/25125/ Accessed on: November 13,2020

Stephenson JM, Du JN, Oliver TK (1970) The effect of cooling on blood gas tensions in newborn infants. The Journal of Pediatrics 76: 848-852. doi:10.1016/S0022-3476(70)80364-X

Sugano $Y$ (1981) Seasonal changes in heat balance of dogs acclimatized to outdoor climate. Jpn Journal Physiology 34: 465-475.
Terrien J, Perret M, Aujard F (2011) Behavioral thermoregulation in mammals: A review. Frontiers in Bioscience 16:1428-1444. doi:10.2741/3797

Trangerud C, Grøndalen J, Indrebø A, Tverdal A, Ropstad E, Moe L (2007) Alongitudinal study on growth variables in dogs of four large breeds raised in domestic environments. Journal of Animal Science 85: 76-83. doi: 10.2527/jas.2006-354

Tuchscherer M, Puppe B, Tuchscherer A, Tiemann U (2000) Early identification of neonates at risk: Traits of newborn piglets with respect to survival. Theriogenology 54: 371-388. doi:10.1016/S0093-691X(00)00355-1

USDA (2013) Animal Welfare Act. In Animal and Plant Inspection Service (p. Title 7).

Vainer BG (2018) A Novel High-Resolution Method for the Respiration Rate and Breathing Waveforms Remote Monitoring. Annals of Biomedical Engineering 46: 960-971. doi:10.1007/s10439-018-2018-6

van der Weyden G, Tavberne M, van Oord R (1986) Changes of jugular blood $\mathrm{pH}$, blood gases, base excess, and body temperature of newborn pups during the first few hours after birth. Tijdschr Diergeneeskd 111:8S-10S.

Vannucchi Cl, Rodrigues JA, Silva LCG, Lúcio CF, Veiga GAL (2012) A clinical and hemogasometric survey of neonatal lambs. Small Ruminant Research 108: 107-112. doi:10.1016/j.smallrumres.2012.05.013

Veronesi MC, Panzani S, Faustini M, Rota A (2009) An Apgar scoring system for routine assessment of newborn puppy viability and short-term survival $\begin{array}{lll}\text { prognosis. Theriogenology 401-407. } & \text { 72: The }\end{array}$ doi:10.1016/j.theriogenology.2009.03.010

Villanueva-García D, Mota-Rojas D, Martínez-Burnes J, Mora MP, Salmeron C, Gómez J, Boscato L, Gutiérrez O, Reyes, B, González-Lozano M (2021) Hypothermia in newly born piglets: Mechanisms of thermoregulation and pathophysiology of death. Journal of Animal Behaviour and Biometeorology 9:2101. doi:10.31893/jabb.21001

Welker WI (1959) Factors influencing aggregation of neonatal puppies. Journal of Comparative and Physiological Psychology 52: 376-380. doi:10.1037/h0047414

Wilborn RR (2018) Small Animal Neonatal Health. In Veterinary Clinics of North America Small Animal Practice 48: 683-699. doi:10.1016/j.cvsm.2018.02.011 